\title{
Duchenne muscular dystrophy: classical and new therapeutic purposes and future perspectives
}

\author{
Distrofia muscular de Duchenne: propostas terapêuticas clássicas e novas e \\ perspectivas futuras
}

Paulo Victor Sgobbi de Souzaํ, Fernando George Monteiro Naylor ${ }^{1}$, Wladimir Bocca Vieira de Rezende Pinto', Acary Souza Bulle Oliveira ${ }^{1}$

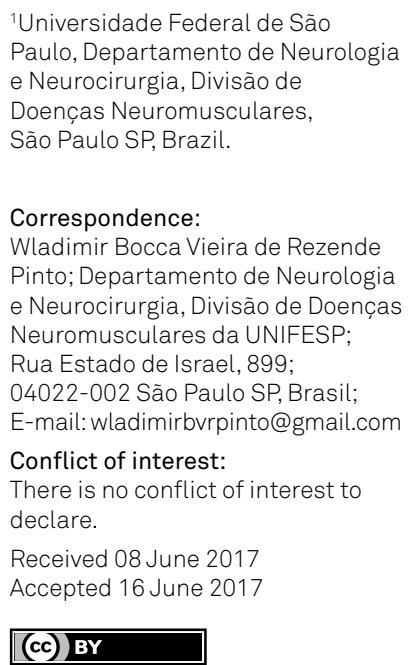

1 Universidade Federal de São Paulo, Departamento de Neurologia e Neurocirurgia, Divisão de Doenças Neuromusculares, São Paulo SP, Brazil.

Correspondence: Wladimir Bocca Vieira de Rezende Pinto; Departamento de Neurologia e Neurocirurgia, Divisão de Doenças Neuromusculares da UNIFESP;

Rua Estado de Israel, 899;

04022-002 São Paulo SP, Brasil; E-mail:wladimirbvrpinto@gmail.com

Conflict of interest:

There is no conflict of interest to declare.

Received 08 June 2017

Accepted 16 June 2017

(cc) BY

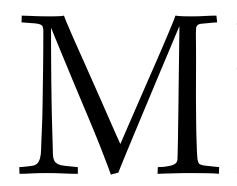

uscular dystrophies represent a wide and expanding group in neurological practice characterized by inherited progressive degenerative myopathy with different patterns of neuromuscular and systemic involvement. Dystrophinopathies represent one of the most important groups both because of their frequence and their high index of clinical morbidity associated with different chronic and severe complications $^{1}$. Duchenne Muscular Dystrophy (DMD) (MIM \#310200) represents the main infancyonset muscular dystrophy with global distribution and a X-linked recessive pattern of inheritance involving mutation in $D M D$ gene (Xp21.2-p21.1), generally associated with one or more deletions of exons resulting in frameshift ${ }^{1}$, giving rise to severe cardiac and neuromuscular compromise, despite the use of most current therapeutic and multidisciplinary approach ${ }^{23}$.

The advent of neurogenetics, new diagnostic methods and emerging therapeutic proposals makes extremely necessary the review of the main consolidated topics on DMD, as well as making guidelines and the adoption of a Brazilian consensus among experts in neuromuscular diseases as a reference for the proper practice of the general neurologist and neuropediatrician. The study provided by Araújo et al., ${ }^{4}$ presented at this issue of Arquivos de Neuro-Psiquiatria represents the most recent attempt of classifying evidence levels and recommendation degrees for different diagnostic and therapeutic aspects related to DMD using a systematic review approach of the current medical literaturesince2010, year of publishing of the last international guideline of $\mathrm{DMD}^{5,6}$.

Authors have proposed as their main results of the consensus: (i) the formal recommendation of genetic testing as the first-line exam to provide diagnosis in suspected cases of dystrophinopathies (e.g. looking for $D M D$ exon deletion/duplication by techniques such as Multiplex Ligation-dependent Probe Amplification/MLPA or Comparative Genomic Hybridizationmicroarray/aCGH, and if necessary next-generation sequencing of $D M D$ gene $^{4,7}$ ), in such a way that muscle biopsy with immunohistochemistry evaluation, classically used as a diagnostic tool by many centers, should be performed in cases in which genetic testing is unavailable or in cases with high suspicion index with undetermined or non-definite diagnostic criteria by prior genetic testing; (ii) the recommendation of using cortico steroids since the diagnosis (e.g. prednisolone, deflazacort, or prednisone), most desirably as early as possible ${ }^{2,48}$; and (iii) reaffirm the importance of special caution before the adoption of the new current therapeutic purposes by the using of exon-skipping ( for the most common genetic situations) and read through agents(in the case of premature stop codon), since most of the results in the studies of such therapies (e.g. Ataluren, Drisapersen, Eteplirsen) still have an unknown impact in the long term for patients and most emerged from studies limited to initial clinical phases 1 and $2^{3,4}$, being essential to extend such randomized clinical trials to phase 3 with a large number of patients.

It is believed that through the results from this consensus clinicians and neuropediatricians can improve their care for patients with dystrophinopathies from the appropriate diagnostic process to the possibility of offering proper drug therapy based on current scientific evidence. 
1. Flanigan KM. Duchenne and Becker muscular dystrophies. Neurol Clin. 2014;32:671-88.

2. Liew WKM, Kang PB. Recent developments in the treatment of Duchenne muscular dystrophy and spinal muscular atrophy. Ther Adv Neurol Disor 2013;6:147-60.

3. Mah JK. Current and emerging treatment strategies for Duchenne muscular dystrophy. Neuropsychiatr Dis Treat. 2016;12:1795-807.

4. Araujo APQC, Carvalo AAS, Cavalcanti EBU, Saute JAm, Carvalho E, França Junior MC et al. Brazilian consensus on Duchenne muscular dystrophy - Part 1: diagnosis, steroid therapy and perspectives. Arq Neuropsiquiatr. 2017;75(8):589-98. https://doi.org/10.1590/0004-282X20170112
5. Bushby K, Finkel R, Birnkrant D, et al. Diagnosis and management of Duchenne muscular dystrophy. Part 1: diagnosis and pharmacological and psychosocial management. Lancet Neurol. 2010;9:77-93.

6. Bushby K, Finkel R, Birnkrant D, et al. Diagnosis and management of Duchenne muscular dystrophy. Part 2: implementation of multidisciplinary care. Lancet Neurol 2010;9:177-189.

7. Aartsma-Rus A, Ginjaar IB, Bushby K. The importance of genetic diagnosis for Duchenne Muscular Dystrophy. J Med Genet. 2016;53:145-51.

8. Rodino-Klapac LR, Mendell JR, Sahenk Z. Update on the treatment of Duchenne muscular dystrophy. CurrNeurolNeurosci Rep. 2013;13:332. 